\title{
LAPORAN KASUS: Investasi Parasit Ancylostoma caninum, Trichuris vulpis dan Ctenocephalides canis Pada Anjing
}

\section{CASE REPORT: Investment Parasites of Ancylostoma caninum, Trichuris vulpis} and Ctenocephalides canis in Dogs

\author{
Atma Hiyal Ulya Ahada ${ }^{1}$, Indra Darpa Kusuma ${ }^{1}$, Reza Yesica ${ }^{2}$. \\ 1Sarjana Kedokteran Hewan, Kandidat Dokter Hewan Fakultas Kedokteran \\ Hewan Universitas Brawijaya \\ ${ }^{2}$ Laboratorium Parasitologi Veteriner Fakultas Kedokteran Hewan Universitas \\ Brawijaya \\ *email: rezayesica@ub.ac.id
}

\begin{abstract}
ABSTRAK
Anjing merupakan salah satu hewan peliharaan manusia yang sering terkena infeksi parasit, baik endoparasit (helminth dan protozoa) maupun ektoparasit (kutu, caplak, pinjal dan tungau). Endoparasit yang sering dilaporkan adalah kasus helminth yaitu Ancylostomiasis, Toxocariasis, Dipylidiasis, Trichuriasis dan Nekatoriasis. Sedangkan ektoparasit khusunya pinjal yang sering ditemui adalah Ctenocephalides canis. Metode yang digunakan untuk mendeteksi adanya cacing adalah pemeriksaan feses secara natif dan apung serta perhitungan Mc Master Chamber untuk mengetahui derajat keparahan infeksi cacing. Pemeriksaan pinjal dilakukan dengan mengidentifikasi preparat basah ektoparasit. Hasil pemeriksaan feses secara apung didapatkan telur cacing Ancylostoma caninum dan Trichuris vulpis. Ektoparasit yang didapat setelah pemeriksaan laboratorik adalah pinjal Ctenocephalides canis. Pengobatan yang dilakukan untuk mengatasi penyakit helminth adalah dengan pemberian obat cacing sedangkan untuk penyakit pinjal dapat dilakukan dengan pemberian obat tetes pinjal. Pencegahan dapat dilakukan dengan pemberian obat cacing secara rutin dan menjaga kebersihan kandang dan lingkungan anjing.

Kata Kunci: Ancylostoma caninum, Ctenocephalides canis, Trichuris vulpis
\end{abstract}

\section{ABSTRACT}

Dogs are one of pets that are often infected by parasites, both endoparasites (helminths and protozoa) and ectoparasites (fleas, ticks, fleas and mites). Endoparasites are frequently reported helminth cases, namely Ancylostomiasis, Toxocariasis, Dipylidiasis, Trichuriasis and Nekatoriasis. Meanwhile, ectoparasites, especially fleas that are often encountered are 
Ctenocephalides canis. The method used to detect the presence of worms is native test, buoyant test and Mc Master Chamber calculations to determine the degree of worm infection severity. Flea investigation is performed by identifying ectoparasite in wet preparations. The results of the floating feces examination showed worm eggs of Ancylostoma caninum and Trichuris vulpis. Ectoparasites obtained after laboratory examination are fleas of Ctenocephalides canis. Treatment for helminth disease is by treatment of worm medicine, while for fleas can be done by provide flea drops medicine. Prevention can be done by therapy of worm medicine regularly and keeping the dog's kennel and environment clean.

Keywords: Ancylostoma caninum, Ctenocephalides canis, Trichuris vulpis

\section{PENDAHULUAN}

Anjing merupakan salah satu hewan domestik yang banyak digemari manusia sebagai hewan kesayangan karena pemeliharaannya yang relatif mudah. Penyakit parasitik merupakan masalah yang paling umum ditemukan pada anjing. Penyakit ini disebabkan oleh parasit, baik endoparasit maupun ektoparasit. Endoparasit dapat berupa manifestasi helmint dan protozoa. Kasus helmintiasis pada anjing yang banyak dilaporkan adalah Ancylostomiasis, Toxocariasis, Dipylidiasis, Trichuriasis dan Nekatoriasis. Ancylostoma caninum, parasit dari filum nematoda, dikenal sebagai cacing usus penghisap darah dan merupakan penyebab utama penyakit cacing tambang anjing di daerah tropis dan subtropics di dunia. Trichuris vulpis (wiphworm) merupakan cacing nematoda yang tersebar luas di seluruh dunia. Pada infeksi berat dapat menyebabkan peradangan pada usus, diare bercampur darah dan lendir, ikhterus dan bias menyebabkan kematian (Kirkova, 2005). Sedangkan ektoparasit yang sering ditemukan pada anjing adalah caplak, kutu, tungau dan pinjal (Hadi dan Rusli, 2006). Pinjal yang sering ditemukan pada anjing adalah Ctenocephalides canis dan Ctenocephalides felis. Pinjal berada pada permukaan tubuh inang saat membutuhkan makanan. Gigitan pinjal dapat mengakibatkan flea allergic dermatitis (Eisen et al., 2008).

\section{Signalemen dan Anamnesa}

Signalemen

Nama Hewan: Diwul

Jenis Hewan: Anjing

Jenis Kelamin: Betina

Ras: Domestik

Warna Rambut: Coklat

Umur: 1 tahun

Berat Badan: 13,65 Kg



Gambar 1. Anjing Diwul

(C)2020. Robbie et al. Open access under CC BY - SA license, doi: 10.20473/mkh.v31i2.2020.85-96 Received: 06-07-2020, Accepted: 23-08-2020, Published online: 29-07-2020 
Anamnesa

Anjing belum pernah diberikan obat cacing dan sudah di steril.

\section{Gejala Klinis dan Pemeriksaan Fisik}

Hasil pemeriksaan fisik menunjukkan bahwa anjing dalam keadaan normal, namun rambut terlihat kusam dan ditemukan adanya ektoparasit. Berikut adalah hasil pemeriksaan fisik anjing Diwul. Gizi: BCS 4

Frekuensi Nadi: 96 kali / menit Frekuensi Nafas: 36 kali / menit Suhu tubuh: $38,7^{\circ} \mathrm{C}$

CRT: $<2$ detik

\section{Diferensial Diagnosa}

Berdasarkan gejala klinis dan pemeriksaan fisik, didapatkan differensial diagnosa yaitu terinfeksi endoparasit dan ektoparasit. Untuk peneguhan diagnosa dilakukan pemeriksaan laboratorium berupa pemeriksaan feses dan identifikasi ektoparasit yang didapatkan.

\section{Pemeriksaan Laboratorik}

Pemeriksaan Laboratorik yang dilakukan untuk memeriksa helminth adalah metode natif, metode apung dan perhitungan Mc Master Chamber. Untuk pemeriksaan ektoparasit dilakukan dengan membuat preparat basah tanpa pewarnaan. Berikut ini adalah metode yang digunakan untuk pemeriksaan:

Pengawetan Basah Ektoparasit

Ektoparasit dimasukkan ke dalam tabung reaksi yang berisi $\mathrm{KOH}$ $10 \%$ selama

24 jam hingga ektoparasit tampak transparan. Kemudian ektoparasit dimasukkan ke dalam alkohol dengan konsesntrasi bertingkat yaitu $30 \%, 50 \%, 70 \%$, 95\%, dan $96 \%$ masing-masing 3-5 menit selanjutnya dicelupkan ke dalam xylol selama 1 menit. Kemudian ektoparasit diletakkan di atas objek glass lalu direkatkan dengan entelan dan ditutup dengan cover glass. Objek glas diberi label pada preparat dan dikeringkan. Kemudian diamati menggunakan mikroskop dengan perbesaran 40x-400x.

Metode Natif

Sampel feses ditetesi aquades lalu diletakkan pada object glass dan tutup dengan cover glass. Kemudian diamati dengan mikroskop 40x-400x.

Metode Apung

Suspensi feses dicampur aqudes dengan perbandingan satu bagian feses dan sembilan bagian aquades. Lalu disaring suspensi menggunakan alat saring dimasukkan kedalam tabung. Tabung disentrifus selama 3 menit dengan kecepatan 1500 rpm dan dibuang supernatannya. Lalu dituangkan larutan garam jenuh 
diatas endapan sampai $1 \mathrm{~cm}$ dari mulut tabung. Kemudian di sentrifus kembali selama 3 menit dengan kecepatan 1500 rpm. Lalu diletakkan tabung di rak, kemudian diteteskan larutan garam jenuh menggunakan pipet tetes sampai permukaan tabung terlihat cembung. Kemudian diletakkan cover glass diatas tabung, dibiarkan selama 1-2 menit lalu di ambil cover glassnya dan diletakkan diatas object glass. Diamati di bawah mikroskop dengan perbesaran 40x-400x.

\section{Metode Mc. Master Chamber}

Feses ditimbang $4 \mathrm{mg}$ dan ditambahkan $26 \mathrm{ml}$ larutan garam jenuh pada becker glass lalu aduk rata. Suspensi feses diaduk dengan pengaduk (magnetic stirrer) sampai rata. Kemudian suspensi feses disaring menggunakan saringan kawat ke dalam gelas piala. Lalu diiambil 0,5-1 $\mathrm{ml}$ filtrat mengunakan spuit ukuran $1 \mathrm{cc}$ dimasukkan ke dalam $M c$ Master Chamber hingga penuh. Lalu di hitung dibawah mikroskop dengan perbesaran 100x dan dilanjutkan dengan rumus perhitungan jumlah telur.

\section{HASIL}

PEMERIKSAAN

\section{LABORATORIK}

Hasil yang didapatkan dari pemeriksaan laboratorik adalah telur cacing Ancylostoma caninum, telur cacing Trichuris vulpis dan ektoparasit Ctenocephalides canis.

1. Ancylostoma caninum Ancylostoma caninum termasuk dalam kelas Nematoda, Familia Ancylostomatidae, genus Ancylostoma. Cacing ini berukuran kecil yang ditandai dengan mulut besar yang menyerang anjing. Predileksi cacing ini berada di intestinum tenue. Siklus hidup cacing ini secara langsung tanpa hospes intermediet. Telur yang keluar bersama feses anjing akan berkembang menjadi larva 3 di lingkungan. Larva 3 merupakan stadium infektif yang bisa menular saat tertelan oleh anjing. Larva 3 akan berkembang selama 2-3 minggu untuk menjadi dewasa ditubuh anjing (ESCCAP, 2017). Berikut ini adalah siklus hidup yang

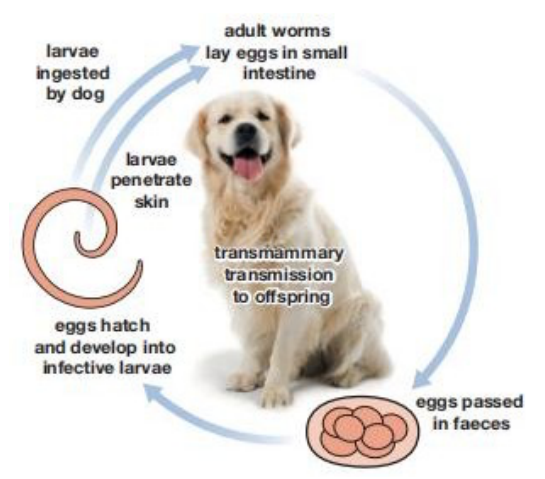

ditunjukkan oleh Gambar 2.

Gambar 2. Siklus Hidup Ancylostoma caninum (ESCCAP, 2017)

(C)2020. Robbie et al. Open access under CC BY - SA license, doi: 10.20473/mkh.v31i2.2020.85-96 Received: 06-07-2020, Accepted: 23-08-2020, Published online: 29-07-2020 
Telur Ancylostoma caninum berbentuk bulat lonjong, berdinding tipis yang terdiri atas 2 lapisan, berukuran 56-75 x 34-47 $\mu \mathrm{m}$, pada waktu dikeluarkan telur telah bersegmen yang terdiri atas 8-16 sel. Berikut ini adalah telur yang ditemukan pada pemeriksaan metode pengapungan yang diamati dengan mikroskop perbesaran 400x dapat dilihat pada Gambar 3.

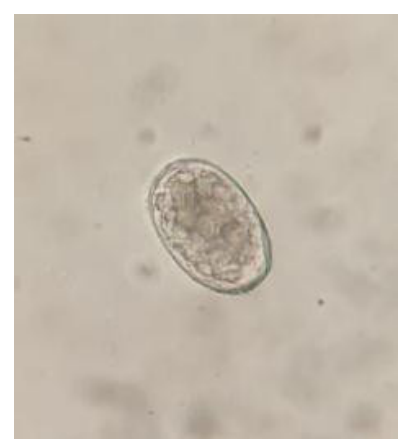

Gambar 3. Telur Ancylostoma caninum. Uji Apung, Perbesaran 100x (Dokumentasi Pribadi)

Patogenesa ancylostomiasis dapat dibagi menjadi 3 kategori yaitu:

Fase Penetrasi Kulit Dermatitis akibat infeksi larva cacing Ancylostoma sp biasanya terjadi di daerah interdigit, kaki dan kadang-kadang di daerah perut. Dermatitis ditandai dengan pruritus, erythema dan papula di kulit. Pada infeksi yang parah, dermatitis akan cepat menyebar ke distal persendian interphalank.

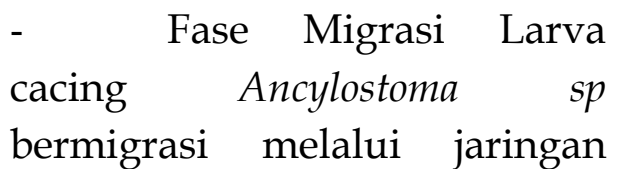

tubuh termasuk paru-paru. Apabila jumlah larva yang bermigrasi cukup banyak maka larva tersebut dapat mengakibatkan gangguan paruparu termasuk saluran pernafasan hingga terjadi batuk. - Fase Intestinal yaitu merupakan infeksi cacing Ancylostoma sp yang dapat menyebabkan anemia, enteritis ringan sampai berat, hypoproteinemia, malabsorbsi usus dan dapat menekan respon kekebalan hospes. Anemia terjadi akibat gigitan cacing Ancylostoma sp yang sekaligus melekat pada mukosa. Cacing dewasa mengigit mukosa usus dengan lokasi yang berpindahpindah dan menyebabkan terjadi pendarahan yang lama karena toksin yang dikeluarkan oleh cacing tersebut. Seekor cacing Ancylostoma sp per hari dapat menghisap darah hospes sebanyak 0,1 $\mathrm{ml}$ bahkan sampai 0,8 ml, dan dapat menyebabkan defisiensi zat besi (Fe) didalam tubuh hewan (Hendrix and Robinson, 2006).

\section{Trichuris vulpis}

Trichuris vulpis termasuk dalam filum nematoda, kelas Enoplea, Familia Trichuridae, genus Trichuris. Predileksi cacing ini berada di usus besar anjing. Kontrol pada cacing ini bisa menjadi sulit, karena anjing dapat terinfeksi kembali jika 
mereka tetap berada di lingkungan yang sama. Siklus hidup cacing ini diawali dari infeksi larva 1 yang menular dan berkembang di dalam telur selama 1-2 bulan pada suhu diatas $4^{\circ} \mathrm{C}$. Telur keluar bersama feses, berkembang menjadi larva infektif di lingkungan. Anjing dapat terinfeksi ketika menelan telur yang telah memasuki stadium infektif, telur tertelan dan menetas di saluran pencernaan dan menjadi dewasa di tubuh anjing (ESCCAP, 2017). Berikut ini adalah siklus hidup yang ditunjukkan oleh Gambar 4.

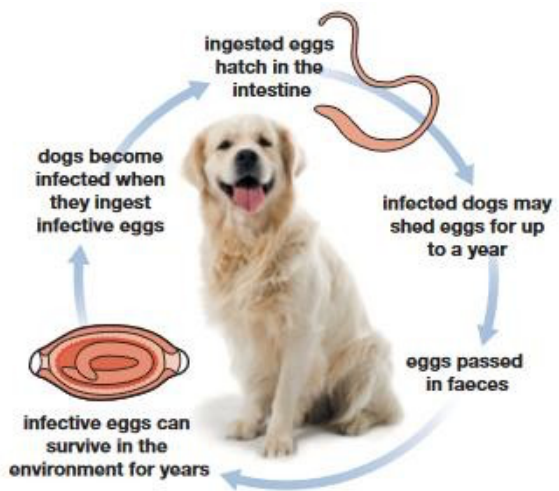

Gambar 4. Siklus Hidup Trichuris vulpis (ESCCAP, 2017)

Telur Trichuris vulpis berukuran 50x25 mm, memiliki bentuk seperti tempayan pada kedua kutubnya terdapat operkulum, yaitu semacam penutup yang jernih dan menonjol. Dindingnya terdiri atas dua lapis bagian dalam jernih dan bagian luar kecokelatan (Dewi, 2007). Berikut ini adalah telur Trichuris vulpis yang ditemukan pada pemeriksaan metode natif dan pengapungan yang diamati dengan mikroskop perbesaran 400x dapat dilihat pada Gambar 5.

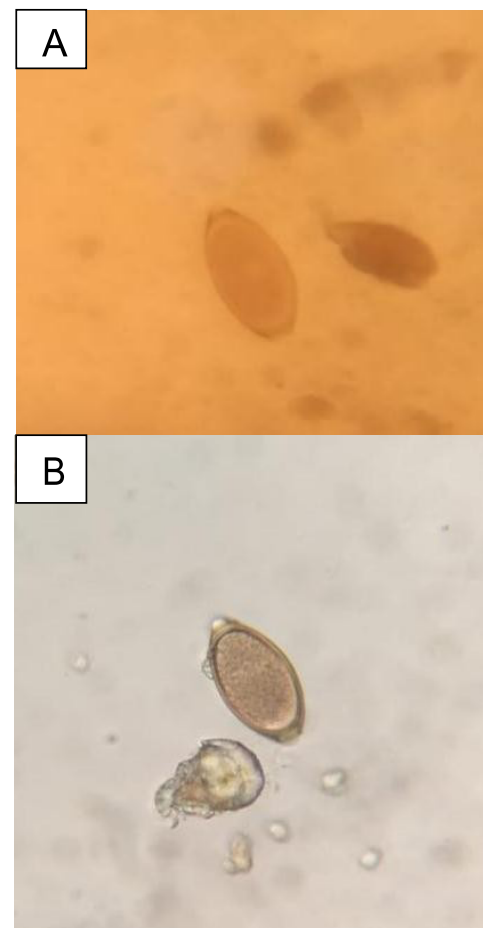

Gambar 5. (A) Telur Trichuris vulpis pada pemeriksaan natif dan (B) Telur

Trichuris vulpis pada pemeriksaan apung (Dokumentasi Pribadi)

Analisis kuantitaif juga dilakukan pada sampel positif spesies telur cacing dari pemeriksaan natif dan apung untuk mengetahui jumlah telur cacing tiap gram feses. Perhitungan dilakukan dengan menggunakan metode McMaster Chamber. Perhitungan dilakukan dengan rumus:

$\frac{\text { Jumlah telur }}{0,3} \times \frac{\mathrm{V}}{\mathrm{m}}=\frac{10}{0,3} \times \frac{30}{4}=750 \mathrm{egg} / \mathrm{gr}$ 
Keterangan

Jumlah telur= total telur yang dapat dihitung pada seluruh kamar hitung 0,3= jumlah kamar hitung yang digunakan $\mathrm{V}=$ Volume cairan $\mathrm{m}=$ berat feses yang tercampur

Pada hasil pemeriksaan feses Trichuris vulpis dengan metode McMaster Chamber dan setalah dilakukan penghitungan.ditemukan 750 telur cacing per gram feses. Menurut WHO (Stephenson et al., 2000) klasifikasi infeksi berdasarkan derajat keparahannya termasuk ringan (1- 999 telur per gram). Hasil pemeriksaan metode Mc Master Chamber telur Trichuris vulpis dapat dilihat pada Gambar 6.

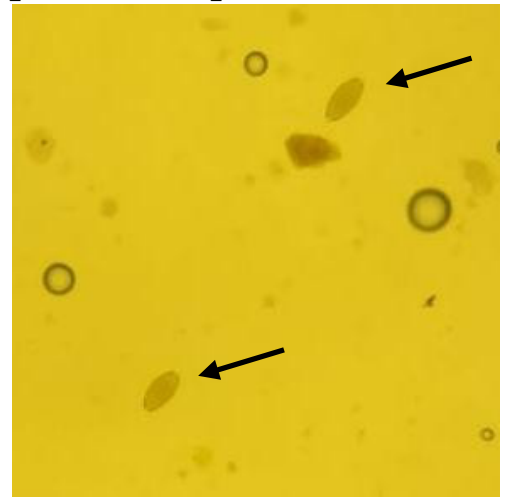

Gambar 6. Telur cacing Trichuris vulpis pada pemeriksaan metode McMaster (Dokumentasi Pribadi)

Patogenesa Trhicuriasis yaitu diawali dengan larva yang memasuki hepar kemudian akan menginduksi kerusakan jaringan pada hepar dan menyebabkan inflamasi. Infiltrasi sel darah putih pada lesi hepar akan terlihat makroskopis yang disebut milk spot. Larva yang menuju pulmo dapat menyebabkan stres pada sistem respirasi yang berujung pada pneumonitis. Gejala klinis yang muncul berupa peningkatan frekuensi pernafasan, dypsnea dan batuk kering. Pada saluran intestin, larva yang baru menetas penetrasi pada sekum dan kolon yang menyebabkan perdarahan pada mukosa. Larva 3 akan berkembang menjadi Larva 4, Larva 5, dan menjadi cacing dewasa pada hari ke-42 post infeksi. Perubahan patologis pada mukosa menyebabkan hipertropi tunika muskularis yang menyebabkan penurunan penyerapan nutrisi (Vandekerckhove, 2018).

3. Ctenocephalides canis

Ctenocephalides canis termasuk dalam filum Arthropoda, kelas Insecta, Ordo Siphonaptera, Familia Pulicidae, Genus Ctenocephalides. Morfologi Ctenocephalides canis berdasar literatur yaitu memiliki bentuk tubuh pipih laterolateral, memiliki 3 pasang kaki, dengan 2 pasang kaki depan pendek dan sepasang kaki belakang panjang (untuk melompat), pada kaki belakang bagian tibia terdapat 2 spina. Bentuk kepala membulat, terdapat 2 comb, yaitu genal comb dan pronatal comb, genal comb pada pinjal tidak sejajar, 
hal itu yang membedakan dengan pinjal Ctenocephalides felis pada anjing (Sasmita, dkk., 2013). Berikut ini adalah Ctenocephalides canis yang diamati dengan mikroskop perbesaran 40x dapat dilihat pada Gambar 7.

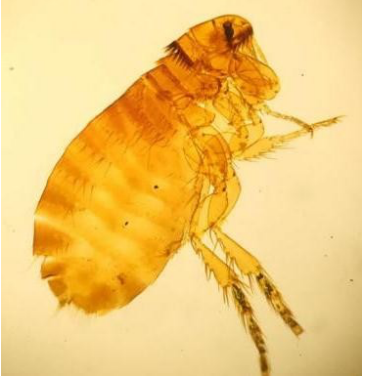

Gambar 7. Ctenocephalides canis perbesaran $40 \mathrm{x}$

Pinjal mengalami metamorfosis sempurna, yang didahului dengan telur, larva, pupa, kemudian dewasa. Pinjal betina akan meninggalkan inangnya untuk meletakan telurnya pada tempat-tempat yang dekat dengan inangnya, seperti sarang tikus atau anjing, celah-celah lantai atau karpet, di antara debu dan kotoran organik, atau kadang-kadang di antara bulu-bulu inangnya. Telurnya menetas dalam waktu 2-24 hari tergantung kondisi lingkungannya. Larva pinjal sangataktif, makan berbagai jenis bahan organik disekitarnya termasuk feses inangnya. Larvanya terdiri atas 3-4 instar (mengalami 2-3 kali pergantian kulit instar) dengan waktu berkisar antara 10-21 hari. Larva instar terakhir bisa mencapai panjang 4-10 $\mathrm{mm}$, setelah itu berubah menjadi pupa yang terbungkus kokon. Kondisi pupa yang berada dalam kokon seperti itu merupakan upaya perlindungan terhadap sekelilingnya. Tahap dewasa akan keluar 7-14 hari setelah terbentuknya pupa. Lamanya siklus pinjal dari telur sampai dengan dewasa berkisar antara 2-3 minggu pada kondisi lingkungsn yang baik. Pinjal dewasa akan menghindari cahaya, dan akan tinggal diantara rambut- rambut inang, pada pakaian atau tempat tidur manusia. Baik pinjal betina maupun jantan keduanya menghisap darah beberapa kali pada siang atau malam hari (Hadi dan Sofiana, 2010).

Ctenochepalides canis dapat menjadi host intermedier untuk cacing pita pada anjing (Dipylidium caninum). Larva pinjal dapat menelan telur cacing pita di lingkungan. Dimana telur cacing dapat menetas dan berkembang juga di dalam usus kucing. Cacing pita berlanjut bertahan dalam tubuh pinjal sampai pinjal menjadi tahap dewasa. Hewan atau manusia dapat memperoleh infeksi cacing pita ketika menelan pinjal yang mengandung kista cacing pita.Infestasi pinjal Ctenochepalides canis pada anjing dapat menyebabkan peningkatan produksi 
hipersensitifitas dan flea allergy dermatitis. Beberapa iritasi pada kulit dapat juga ditemukan akibat dari garukan, menyebabkan rambut rontok,peradangan, infeksi sekunder dan terjadinya pigmentasi pada beberapa kasus. Infestasi pinjal pada anjing lebih mungkin diperoleh dari lingkungan daripada kontak dengan anjing lain (Linardi, 2012).

\section{Diagnosa}

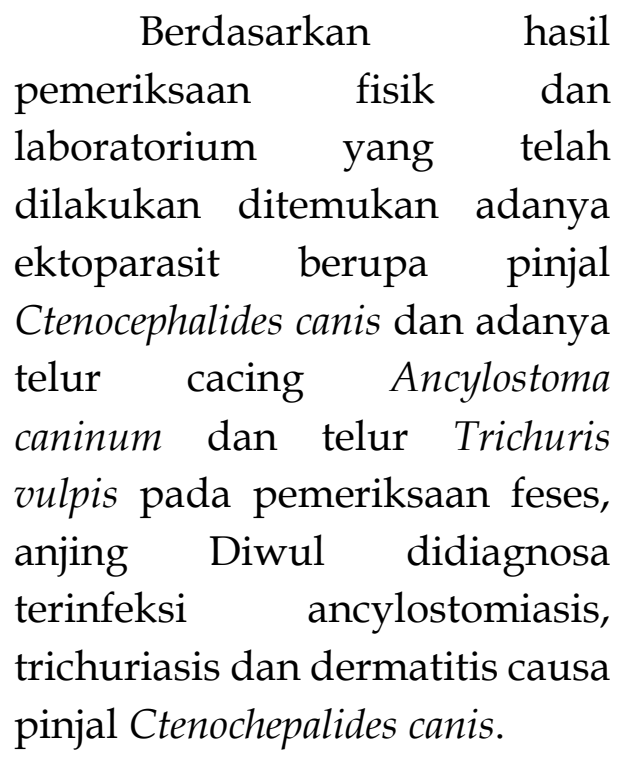

\section{Terapi dan Pencegahan}

Terapi yang digunakan adalah obat-obatan antelmintik berspektrum luas seperti mebendazol. Mebendazol bekerja sebagaai vermisid, larvisid, dan ovisid, yang sangat efektif terhadap cacing kremi, gelang, pita, cambuk, dan cacing tambang. Pencegahan infeksi cacing dapat dilakukan dengan pemberian obat cacing secara rutin (Tan dan Rahardja, 2007).

Terapi yang dapat diberikan untuk mengatasi infeksi kutu dan pinjal dapat dimandikan dengan sampo khusus untuk anti ektoparasit, maupun juga dapat diberikan terapi injeksi atau tetesan obat pada tengkuk yang mengandung ivermectin atau selamectin. Untuk pencegahan pinjal dapat dilakukan dengan menjaga kebersihan lingkungan dan memandikan anjing dengan shampo anitparasit secara rutin untuk memutus siklus hidup dari pinjal (Linardi, 2012).

\section{KESIMPULAN}

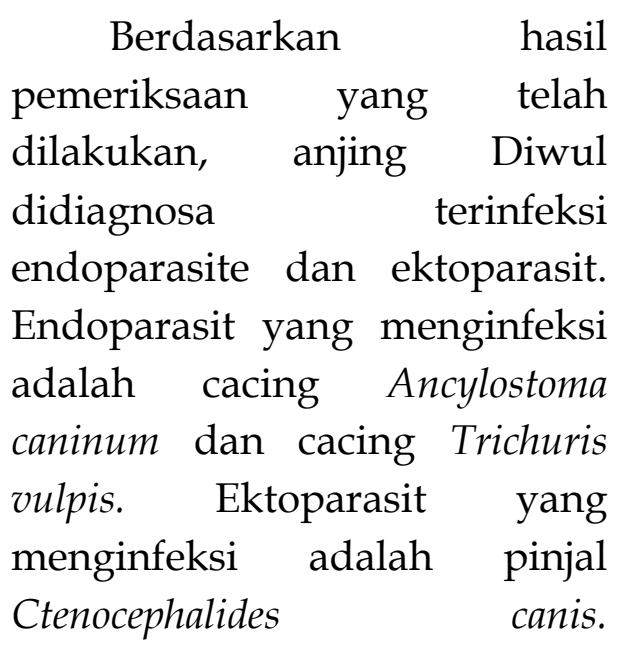

Pengobatan infeksi Ancylostoma caninum dan Trichuris vulpis dapat dilakukan dengan pemberian obat anti helminth seperti Mebendazole. Pengobatan anjing yang terkena pinjal dapat dilakukan dengan memandikan anjing dengan shampo anti ektoparasit atau dengan obat tetes yang mengandung ivermectin atau 
selamectin.

\section{DAFTAR PUSTAKA}

Dewi, Kartikan dan R.T.P. Nugraha. 2007. Endoparasit Pada Feses Babi Kutil ( Sus Verrucosus). Vol.16(1):1319. Jakarta

Eisen, R. J., et al. 2008. Earlyphase Transmission of Yersinia pestisby Cat Fleas (Ctenocephalides felis) and Their Potential Role as Vectors in a Plagueendemic Region of Uganda.Am J Trop Med Hyg.78(6):949-956.

ESCCAP, 2017. Worm Control in Dogs and Cats. Malvern Hills Science Park, Geraldine Road, Malvern, Worcestershire.

Hadi, U. K., Soviana S. 2010. Ektoparasit Pengenalan, Identifikasi, dan Pengendaliannya. IPB Press, Bogor. Hadi UK, Sigit SH. 2006. Hama dan Permukiman

Hadi, U. K., Rusli VL. 2006. Infestasi caplak anjing Rhipicephalus sanguineus (Parasitiformes: Ixodidae) di daerah Kota Bogor J Med Vet Indones. 10(2):5560.

Kirkova, Z., et al. 2005. Clinical and Haematological Studies in Dogs, Experimentally Infected with Trichuris vulpis.

Bulgarian Journal of Veterinary Medicine8 (2): 141-148.

Linardi, P. M, Santos, J. L. C. 2012. Ctenocephalides felis vs. Ctenocephalides canis (Siphonaptera: Pulicidae): Some Issues In Correctly Identify These Species. Rev. Bras. Parasitol. Vet., Jaboticabal, 21(4): 345-354.

Sasmita, R., Hastutiek, Pudjie, Sunarso, Agus, dan Yunus, Muhammad. 2013. ARTHROPODA VETERINER. Airlangga University Press, Surabaya. Tan dan Rahardja. 2007. ObatObat Penting: Khasiat, Penggunaan dan Efek Sampingnya. Penerbit Elex Media Komputindo. Jakarta.

Vandekerckhove, Elise. 2018. Thesis: The Use of Serology in the Control of Ascaris suum Infections in Pigs. Salisburylaan:

Universiteit Gent.

(C)2020. Robbie et al. Open access under CC BY - SA license, doi: 10.20473/mkh.v31i2.2020.85-96 Received: 06-07-2020, Accepted: 